\title{
Applying Case Method in the Training of Future Specialists
}

\author{
Mykhailo Chumak ${ }^{1, *}$, Serhii Nekrasov², Nataliia Hrychanyk ${ }^{3}$, Viktoriia Prylypko ${ }^{4} \&$ Vasyl Mykhalchuk ${ }^{5}$ \\ ${ }^{1}$ Educational and Research Institute of Commerce, Serving Technology and Tourism, Luhansk Taras Shevchenko \\ National University, Starobilsk, Ukraine \\ ${ }^{2}$ Sumy State University, Sumy, Ukraine \\ ${ }^{3}$ Educational and Scientific Institute of Philology and History, Oleksandr Dovzenko Hlukhiv National Pedagogical \\ University, Hlukhiv, Ukraine \\ ${ }^{4}$ Kremenchuk Mykhailo Ostrohradskyi National University, Kremenchuk, Ukraine \\ ${ }^{5}$ Shupyk National Healthcare University of Ukraine, Kyiv, Ukraine \\ *Correspondence: Educational and Research Institute of Commerce, Serving Technology and Tourism, Luhansk Taras \\ Shevchenko National University, Starobilsk, 92703, Ukraine. E-mail: chumakmike8@ukr.net
}

Received: December 9, 2021

Accepted: January 6, 2022 Online Published: January 17, 2022

doi:10.5430/jct.v11n1p235

URL: https://doi.org/10.5430/jct.v11n1p235

\begin{abstract}
Making a brighter presentation and improving assimilation of educational material with the help of the case method allows activating the mental, exploratory and creative abilities of students to optimize the process of assimilation of information. The combination of this method with others allows making future specialists to independently find ways to solve problems. This results in the assimilation of professionally significant special knowledge. The aim of the study was to determine the features of the application of the case method in the educational process in preparing students for future professional activities, identifying sources, structural elements and filling professional cases. The study involved the survey method and further testing to identify indicators of significance at the summative and control stage of the experiment. Methods used: diagnostic programme to study the level of educational activities by Riepkina, Zaika; assessment of the level of control and self-assessment actions; statistical and mathematical interpretation of empirical data with subsequent functional analysis of the research results. The study showed the high efficiency of the case method in the educational environment of higher educational institutions (HEIs). The indicator of students' self-presentation after the application of the case method has changed significantly. This was reflected in an increased high level to $35.5 \%$, a decreased medium level to $38 \%$, and a slight increase in all levels in the experimental group students. Positive dynamics was revealed on all criteria for diagnosing the effectiveness of the case method in teaching: a decreased percentage of students with negative and relatively low markers and a corresponding increase in the percentage of students with positive markers of knowledge and learning the material. Further research can deal with development and implementation of case systems in view of certain majors, taking into account future professional activities.
\end{abstract}

Keywords: case method, future specialists, educational process, higher educational institution, professional training

\section{Introduction}

The active transformation of modern society requires changes in the process of both general professional training and the system of higher education. The volume of accumulated knowledge is constantly increasing, the requirements for specialists of all majors are changing. At the present stage of development it is important that a qualified specialist not only has certain knowledge and skills, can confidently use them in professional activities, but also is able to competently and appropriately operate new data, think logically, solve problems of varying complexity, constantly self-improve.

As practice shows, the quality training is possible provided the integration of theory and practice in the educational process, with priority given to practical, applied orientation of education, as the main task of higher professional education is to train specialists who have a set of competencies needed for quality professional activity. Accordingly, the search for new forms, methods and technologies that can improve this process. That is why much attention is paid 
to "activity" (interactive) teaching methods that can motivate students to study the subject, increase cognitive activity, as well as give the opportunity to apply the theoretical knowledge in practice.

The case method is one of the most relevant, popular and, most importantly, effective interactive teaching methods, which, according to researchers, promotes critical thinking, enhances teamwork, promotes collaboration and cooperation of students and teachers, improves professional knowledge and skills. That is why this study deals with the problem of applying the case method in the educational process in HEIs of Ukraine.

The problem of practice-oriented training of specialists is urgent not only for our country. As a rule, MBA (Master of Business Administration) programmes mean the specialized education of managers abroad. The content of these programmes is largely standardized, so it is suitable for training managers around the world. MBA programmes based on the achievements of advanced foreign business schools are presented in many HEIs in the country.

Critics of the MBA system argue that modern business schools are more focused on learning about specific business functions, while it is necessary to pay more attention to management practice and to acquire these skills at directly in the workplace. This is due to the fact that no one has yet managed to create a leader in the classroom. Managers need to perceive things in their full life cycle, not in separate "packages". So, the application of the case method can help to improve the shortcomings of the MBA system. The study of the effectiveness of the applying the case method in the training of managers in the MBA programme is very relevant today.

The aim of the study is to clarify the features of applying case method in the educational process in preparing students for future professional activities, identifying sources, structural elements and filling professional cases.

The research objectives are the following:

1) Organization and carrying out organizational-pedagogical and methodical actions to determine the reasonability of applying a case-method in educational process of future specialists in HEIs;

2) Determining the optimal structure and filling cases for future specialists of different majors;

3. Conducting a qualitative and quantitative analysis of the indicators of the study.

\section{Literature Review}

In modern pedagogical science, the case method is defined as a method of active problem-situational analysis, which is based on the organization of the educational process by completing certain assignments/ solving problems/ situations that may arise in the professional sphere (Akipova, 2020).

There are several opinions on the essence of the phenomenon of "case method" among scientists, they include:

- Case method is a discussion of various every-day or professional cases (Dian, 2020);

- analysis of particular situations (Filimonova, 2021);

- analysis of a specific event in order to arrange a discussion and involve all participants in the search for the best solution (Nowiński et al., 2019; Trejo-Pechi \& White, 2017);

- educational material, which presents a situation or case with a significant problem that needs to be addressed (Moreira, 2017);

The case method is based on two terms - "case" and "study", which form a single field — "case study" (Andersen \& Sciano, 2017). So, the purpose of such a method is to analyse a specific situation that arises under certain conditions, and the choice of a practical solution to the proposed problem with its subsequent analysis.

The case method combines theory and practice into educational assignments that are discussed and completed mainly in small groups, and, most importantly, theoretical material is not only illustrated with examples, but learnt during the study and analysis of specific examples of professional field (Mahdi et al., 2020; Plakhina, 2017; Talukdar, 2020).

There are currently two classical schools that analyse the use of the case method in teaching — Harvard (American) and Manchester (European). The first school sets the goal of teaching how to find the right solution using large cases. The second school provides a variety of solutions to the problem, and the description of the situation can be presented in a small case. The practical situations can be developed in two ways: on the basis of a description of real events and/or on the basis of artificially simulated situations (Daradkeh \& Rakhimbekova, 2017; Roszkowska \& Filipowicz-Chomko, 2021).

Summarizing and systematizing the views of scholars, we note that in our study we will interpret the case method as 
a specific pedagogical technology, which is based on simulation of the situation that may arise in the professional sphere in order to find solutions. The purpose of the case method can be understood as a joint discussion of a certain event/situation that occurs in everyday professional activities and finding the optimal solution to this problem (Harrison, 2019; Lang 2014).

According to Wei and $\mathrm{Wu}(2019)$, the case method is an educational prospect in which research potential develops and which opens up the opportunities. Modelling of professional situations that allows future specialists not only to solve the problem, but also to build tactics of behaviour under certain circumstances, to predict the further development of the situation, to develop teamwork skills, the ability to express their own opinions and defend their positions, make arguments, lead discussions, etc.

\section{Methods and Materials}

A study to confirm the reasonability of applying case methods in the educational process was conducted in three Ukrainian HEIs during 2020-2021.

The following methods were used for the survey: diagnostic programme to study the level of educational activities H.V. Riepkina, Ye.V. Zaika; assessment of the level of control and self-assessment actions. The distributions of the results of the experimental group were characterized by shifts in the medians relative to the normal statistical distribution at the initial $\left(\Delta \mathrm{M}_{1}\right)$ and final $\left(\Delta \mathrm{M}_{2}\right)$ stages of the experiment. The discrepancy of the medians was calculated: $\mathrm{R}=\Delta \mathrm{M}_{2}-\Delta \mathrm{M}_{1}$ and compared with the corresponding indicator of the control group (C), which is given in parentheses.

Students of different faculties and majors took part in the research. The study was conducted at the Department of Mechanical Engineering, Machines and Tools of the Faculty of Technical Systems and Energy Efficient Technologies (Sumy State University), the Department of Ukrainian Language, Literature and Teaching Methods of the Educational and Scientific Institute of Philology and History (Oleksandr Dovzhenko Hlukhiv National Pedagogical University), the Department of Basic and Branch Legal Sciences of the Faculty of Law, Humanities and Social Sciences (Kremenchuk Mykhailo Ostrogradskyi National University).

The participants of the experiment were divided into the control (CG) and experimental groups (EG) numbering 100 people each. It should be noted that for the reliability of the experiment, the conditions and organization of training of future specialists in these HEIs were the same: there were students with different levels of education in the groups. Prior to the experiment, they all studied according to a single curriculum and work programme.

The experimental study consisted of a series of successive stages - summative, formative and control. The summative stage was aimed at identifying the level of professional and creative abilities, intellectual activity of selected categories of students, as well as clarifying the pedagogical conditions for the effective implementation of further future professional activities. The methods of testing and survey of students of selected HEIs were used for the organization and implementation of the summative stage.

The control stage of the experiment involved statistical processing and analysis of research data using STATISTICA 13.3, as well as making recommendations on the use of the case method in the further educational process of specialists in various fields in HEIs of Ukraine.

\section{Results}

Prior to the experiment, students of the experimental and control groups were conditionally differentiated into three levels - high, medium and low. This was due to the need for more representative survey results by taking into account the individual characteristics of respondents. High-level students had the ability to study creatively, had critical and logical thinking skills, the ability to establish cause-and-effect relationships of the studied objects, and so on. During classes, such students were active, attentive, focused, had a steady cognitive interest. The medium level included students who had partial activity during the educational process in HEIs and the search type of educational activity, showed increased interest only in certain topics. Low-level students were passive in classes, had low concentration and reproductive type of learning activities. Comparative CG and EG data by levels are shown in Figure 1. 


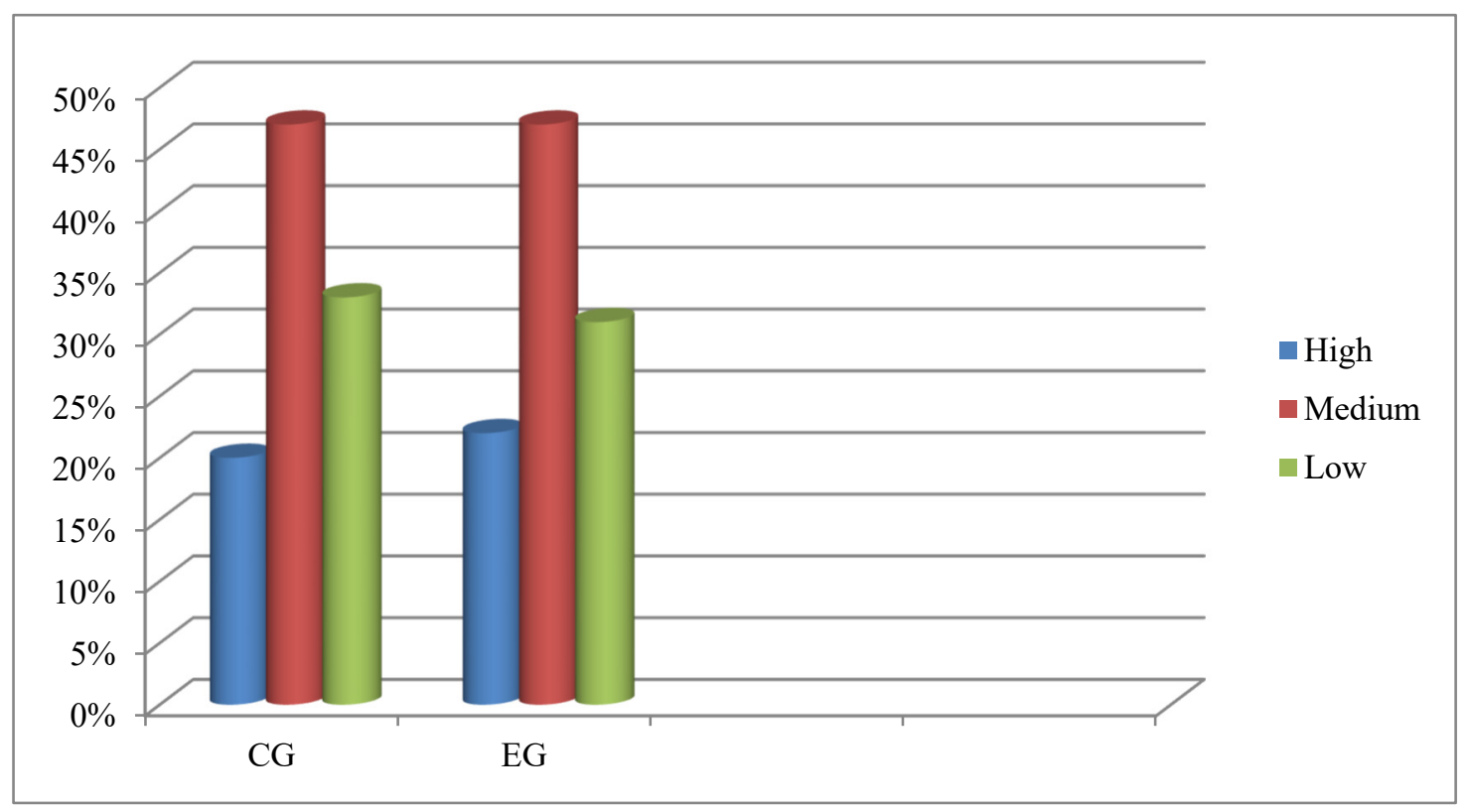

Figure 1. Distribution of Respondents by Representation Levels

Source: Compiled by the authors based on the survey results

The testing method was used to assess the level of learning material. The prepared test contained assignments for students of each level of learning material, which ensured the accuracy of the obtained data. Students who made 0-1 error obtained an "excellent" grade, "good" - 2-3 errors, "satisfactory" - 4-5, "unsatisfactory" - more than 5 errors. Summarized results of testing in percentage are shown in Figure 2.

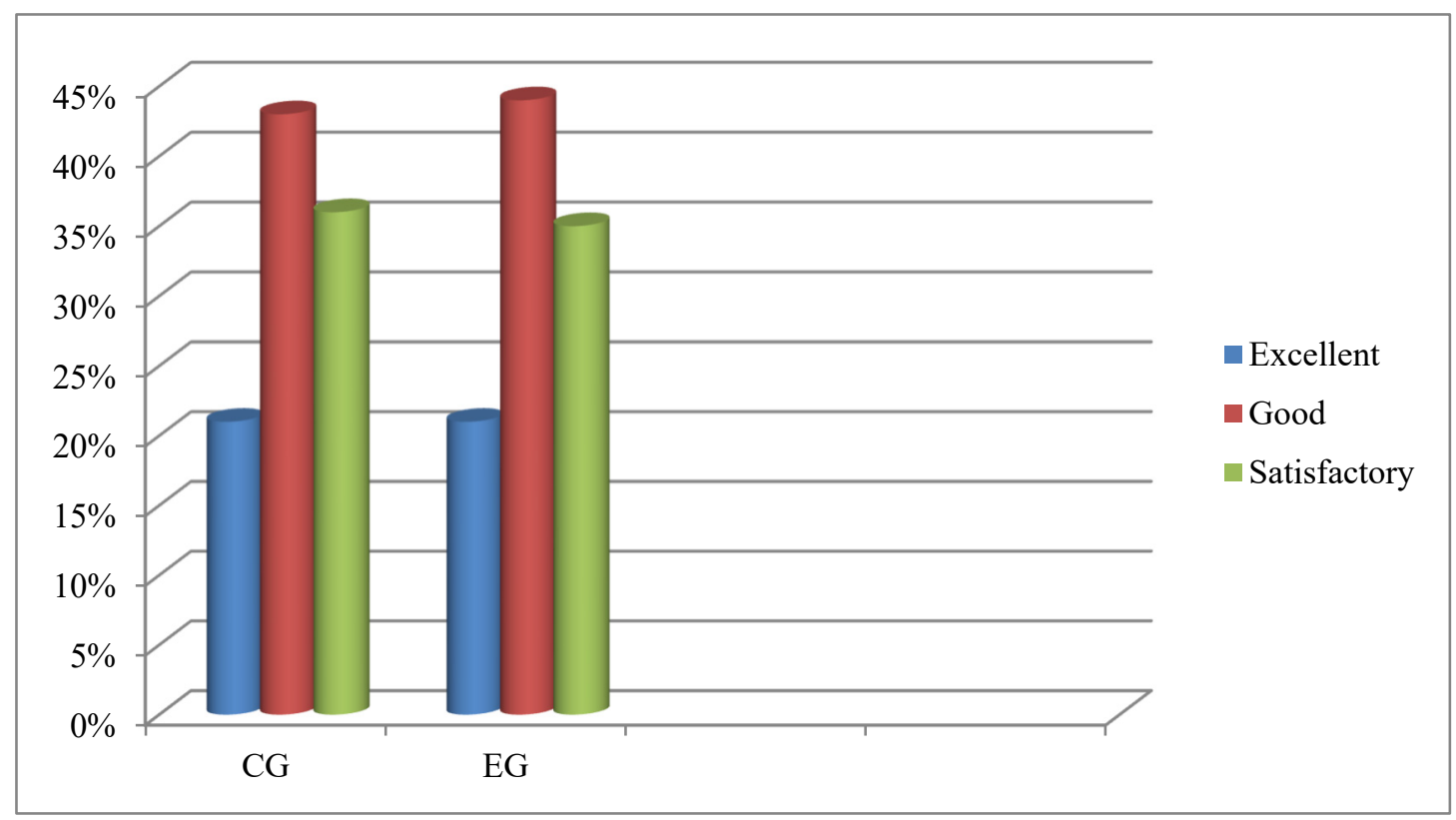

Figure 2. Distribution of Respondents by the Obtained Grades

Source: Compiled by the authors based on the survey results

The analysis of the summative stage of the experiment allowed drawing the following conclusions: no statistically significant differences in the values of indicators in the groups were found. The results obtained at the summative stage guaranteed greater accuracy of the indicators of the formative stage of the experiment. The results of the final testing 
showed better learning success in the experimental group compared to the control one. The summary results are shown in Figure 3.

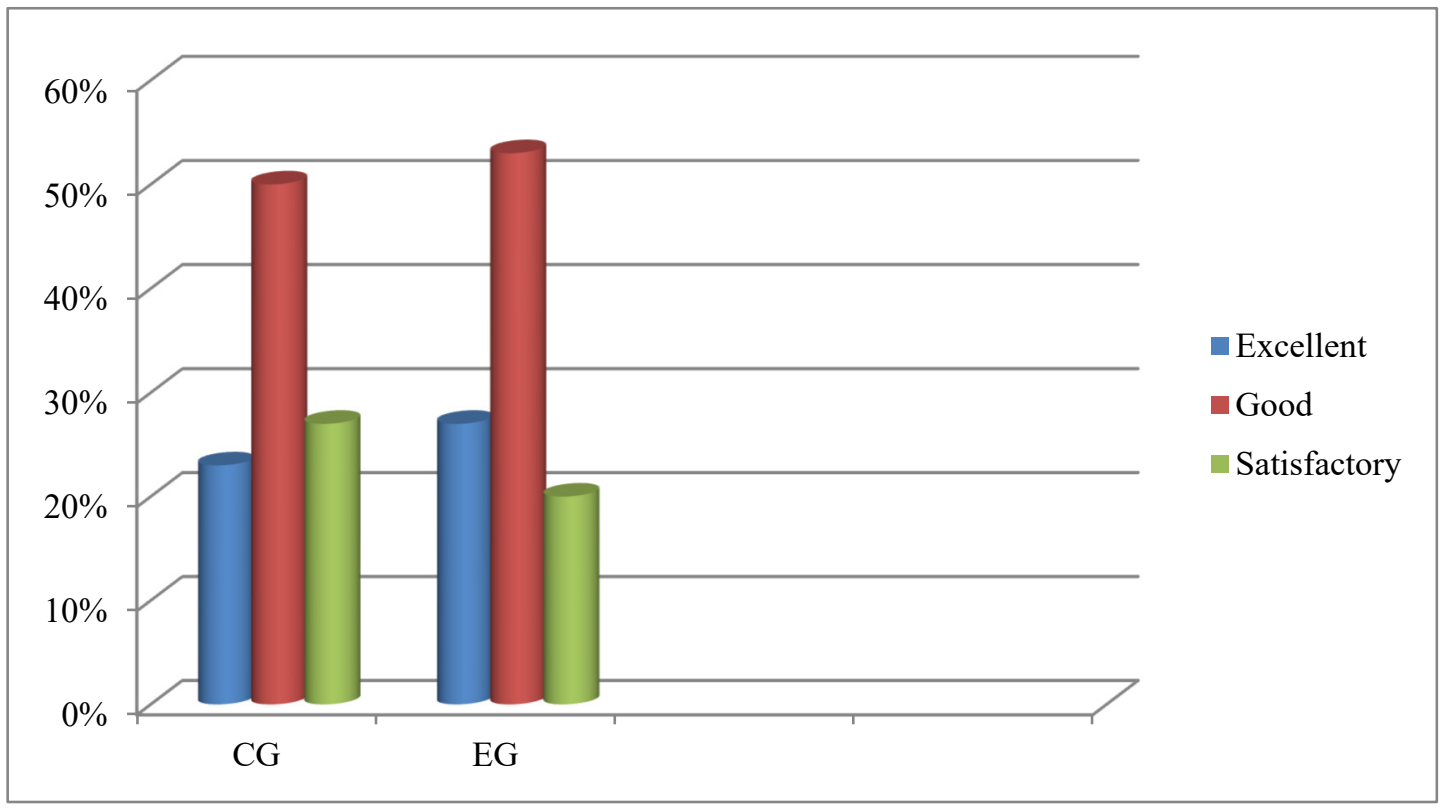

Figure 3. Distribution of Respondents by the Obtained Grades

Source: Compiled by the authors based on the survey results

Control and self-assessment actions of students are a component of the case method, its indicator is the self-presentation of the project and implementation in the student's life. Comprehensive answers of students at a high level made up $12 \%$ of the experimental group. When asked about the result of the project as defining competencies, students listed the ability to make a project plan, determine the purpose, the ability to identify a problem situation, a hypothesis. Students connect the product of the project with everyday life. Quantitative data are presented in Table 1.

Table 1. The Level of Control and Self-Assessment Actions of Students - Their Self-Presentation

\begin{tabular}{|c|c|c|c|c|}
\hline \multirow{3}{*}{ Indicator of projective culture } & \multirow{3}{*}{ Groups } & \multicolumn{3}{|c|}{ Levels } \\
\hline & & High & Medium & Low \\
\hline & & \multicolumn{3}{|c|}{ Beginning/End of the experiment (\%) } \\
\hline \multirow[t]{2}{*}{ Actual reflexive control } & E & 23.9/36.2 & $45.8 / 45.6$ & $30.3 / 18.2$ \\
\hline & $\mathrm{C}$ & $18 / 15$ & $43 / 47$ & $39 / 38$ \\
\hline \multirow[t]{2}{*}{ Actual and adequate prognostic assessment } & E & $18 / 47$ & $43 / 37$ & $39 / 16$ \\
\hline & $\mathrm{C}$ & $8 / 19.5$ & $37 / 56$ & $55 / 23$ \\
\hline \multirow[t]{2}{*}{ Self-fulfilment } & $\mathrm{E}$ & $10 / 45.5$ & $69 / 31$ & $21.5 / 23.5$ \\
\hline & $\mathrm{C}$ & $4.5 / 12$ & $67 / 59$ & $28.5 / 29$ \\
\hline \multirow[t]{2}{*}{ Total } & E & $10.0 / 45.5$ & $69 / 31$ & $21.0 / 23.5$ \\
\hline & $\mathrm{C}$ & $4.5 / 12.0$ & $67 / 59$ & $28.5 / 29.0$ \\
\hline
\end{tabular}

Source: Compiled by the authors based on the survey results

Based on the results of the initial and final stage of the study, the levels of students' control and self-assessment competencies - their self-presentation on three components - were established through diagnostic methods:

- the level of control of projective actions on the actual reflexive control;

- the level of the assessment of project actions on the actual-adequate prognostic assessment;

- self-presentation of the project, realization of the project significant for the student (Table 2). 
Table 2. Formation of Control and Self-Assessment Actions - Their Self-Presentation

\begin{tabular}{|c|c|c|c|c|c|c|c|c|c|c|c|c|c|c|c|c|}
\hline \multirow{3}{*}{$\begin{array}{l}\text { Item } \\
\text { No. }\end{array}$} & \multicolumn{6}{|c|}{ Initial stage of the study } & \multicolumn{7}{|c|}{ Final stage of the study } & \multirow{3}{*}{$\Delta \mathrm{M}_{2}$} & \multirow{3}{*}{\multicolumn{2}{|c|}{$\mathrm{R}$}} \\
\hline & \multicolumn{2}{|c|}{ High } & \multicolumn{2}{|c|}{ Medium } & \multicolumn{2}{|c|}{ Low } & \multirow[t]{2}{*}{$\Delta \mathrm{M}_{1}$} & \multicolumn{2}{|c|}{ High } & \multicolumn{2}{|c|}{ Medium } & \multicolumn{2}{|c|}{ Low } & & & \\
\hline & E & $\mathrm{C}$ & E & $\mathrm{C}$ & $\mathrm{E}$ & $\mathrm{C}$ & & E & $\mathrm{C}$ & $\mathrm{E}$ & $\mathrm{C}$ & $\mathrm{E}$ & $\mathrm{C}$ & & & \\
\hline 1 & $\underset{\omega}{N}$ & $\ddot{\infty}$ & $\underset{\infty}{\stackrel{\vec{\infty}}{ }}$ & $\stackrel{t}{0}$ & $\underset{i}{\stackrel{w}{\omega}}$ & $\begin{array}{l}\omega \\
.0 \\
0\end{array}$ & 's & $\begin{array}{l}\tilde{N} \\
\stackrel{\omega}{n}\end{array}$ & $\vec{u}$ & $\begin{array}{l}\overrightarrow{1} \\
\dot{\sigma}\end{array}$ & $\stackrel{t}{\vec{t}}$ & $\begin{array}{l}\vec{\infty} \\
\dot{\sim}\end{array}$ & $\begin{array}{l}\omega \\
\infty \\
0\end{array}$ & $t$ & $\stackrel{I}{E}$ & $\stackrel{ \pm}{N}$ \\
\hline 2 & $\ddot{\infty}$ & $\stackrel{\infty}{0}$ & $\underset{\omega}{+}$ & $\underset{0}{w}$ & $\begin{array}{l}w \\
.0 \\
0\end{array}$ & ú & 士 & $\stackrel{\Delta}{\Delta}$ & in & $\underset{0}{w}$ & पू & $\vec{a}$ & $\stackrel{N}{\oplus}$ & $\frac{ \pm}{\sigma}$ & $\underset{\text { I }}{\stackrel{J}{J}}$ & $\stackrel{+}{\mathrm{V}}$ \\
\hline 3 & : & $\stackrel{\Delta}{i r}$ & $\begin{array}{l}8 \\
0\end{array}$ & $\begin{array}{l}9 \\
0\end{array}$ & $\stackrel{N}{\circ}$ & $\begin{array}{l}N \\
\infty \\
\text { in }\end{array}$ & à & $\begin{array}{l}\text { 品 } \\
\text { un }\end{array}$ & $\stackrel{n}{0}$ & $\underset{0}{\omega}$ & $\begin{array}{l}\text { U్ } \\
0\end{array}$ & $\begin{array}{l}\sim \\
\text { in }\end{array}$ & $\begin{array}{l}N \\
0 \\
0\end{array}$ & \pm & 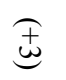 & \pm \\
\hline
\end{tabular}

Source: Compiled by the authors based on the survey results

The study showed that students of both control and experimental groups have low levels of cognitive, emotional-value and projective-reflexive components of the projective culture (Table 3 ).

Table 3. Comparative Analysis of Indicators of Projective Culture

\begin{tabular}{|c|c|c|c|c|c|c|c|c|c|c|c|c|c|c|c|c|}
\hline \multirow{3}{*}{$\begin{array}{l}\text { Item } \\
\text { No. }\end{array}$} & \multicolumn{6}{|c|}{ Initial stage of the study } & \multirow{3}{*}{$\Delta \mathrm{M}_{1}$} & \multicolumn{6}{|c|}{ Final stage of the study } & \multirow{3}{*}{$\Delta \mathrm{M}_{2}$} & \multirow{3}{*}{\multicolumn{2}{|c|}{$\mathrm{R}$}} \\
\hline & \multicolumn{2}{|c|}{ High } & \multicolumn{2}{|c|}{ Medium } & \multicolumn{2}{|c|}{ Low } & & \multicolumn{2}{|c|}{ High } & \multicolumn{2}{|c|}{ Medium } & \multicolumn{2}{|c|}{ Low } & & & \\
\hline & $\mathrm{E}$ & $\mathrm{C}$ & $\mathrm{E}$ & $\mathrm{C}$ & $\mathrm{E}$ & $\mathrm{C}$ & & $\mathrm{E}$ & $\mathrm{C}$ & $\mathrm{E}$ & $\mathrm{C}$ & $\mathrm{E}$ & $\mathrm{C}$ & & & \\
\hline 1 & $\stackrel{v}{v}$ & $\stackrel{\square}{ \pm}$ & $\stackrel{\overrightarrow{0}}{\circ}$ & $\stackrel{\text { Uి }}{\underset{\nu}{\nu}}$ & $\frac{u}{a}$ & Na & 离 & $\underset{\omega}{w}$ & $\vec{a}$ & $\underset{\omega}{\omega}$ & $\begin{array}{l}\text { U్ } \\
0\end{array}$ & $\begin{array}{l}\text { No } \\
\text { in }\end{array}$ & $\begin{array}{l}N \\
0 \\
0\end{array}$ & $\stackrel{+}{\perp}$ & $\stackrel{Ð}{\Xi}$ & $\stackrel{+}{\sigma}$ \\
\hline 2 & $\underset{\infty}{N}$ & 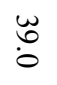 & $\stackrel{\circ}{\circ}$ & 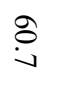 & $\overrightarrow{\text { in }}$ & $\stackrel{N}{+\infty}$ & + & $\begin{array}{l}\omega \\
\infty \\
\omega\end{array}$ & $\underset{\forall}{\Xi}$ & $\frac{u}{\infty}$ & 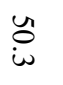 & ర6 & $\stackrel{w}{N}$ & $\underset{\perp}{ \pm}$ & $\stackrel{I}{\oplus}$ & \pm \\
\hline 3 & $\vec{v}$ & ○ & $\begin{array}{l}\vec{b} \\
\dot{0}\end{array}$ & $\stackrel{u}{\stackrel{N}{a}}$ & $\stackrel{\omega}{\circ}$ & $\stackrel{\oplus}{\circ}$ & la & $\stackrel{\stackrel{N}{\sim}}{\sim}$ & $\stackrel{\omega}{\sim}$ & $\stackrel{\oplus}{\infty}$ & $\underset{\infty}{\stackrel{u}{\infty}}$ & $\vec{a}$ & $\underset{⿱ 中}{\stackrel{w}{*}}$ & $\stackrel{ \pm}{\omega}$ & I্ & $\frac{+}{\sigma}$ \\
\hline
\end{tabular}

Source: Compiled by the authors based on the survey results

At the beginning of the study, no statistically significant differences were found between the results of the control and experimental groups. This is due to the inclusion of the case method in the activities of all participants in the experiment.

\section{Discussion}

The conducted experimental research and a number of formative measures showed an increase in the indicators of learning educational material after the introduction of the case method in the classes. The dynamic structural and substantive model of students' projective culture provides a holistic, systemic construct as a set and interdependence of three blocks: conceptual, in-class and extracurricular activities. Included in the context of structural components: cognitive, emotional-value, projective-reflexive, presented in accordance with the age characteristics of students of the MBA programme. Projective activity of students consists in development and realization of life-creating projects (system of the planned and realized actions, necessary conditions and means of achievement of the set goals) in educational process. During classes students master the available methods of projective activity by means of case-methods, which includes the choice of the project idea; definition of the goal and objectives of the project; comprehension of the problem situation; hypothesis formulation; verification — testing a hypothesis through a description of the work. 
The obtained results of the experiment allowed making certain generalizations, namely:

1. Case studies can be actively implemented from the third year, when students have already formed a certain system of professional knowledge, and the leading role is given to the study of specialized subjects. It is necessary to start with simple, linear cases with a limited number of assignments, gradually complicating and adding broader and deeper reasons for reflection (Hua \& Ren, 2020; Huang et al., 2021; Vinokurova et al., 2020).

2. Certain types of cases are distinguished according to the levels of introducing cases. First of all, these are:

- Practical cases designed to facilitate the modelling of real life situations. In other words, these are cases of situational modelling of the problem of the professional sphere that needs to be solved. The purpose of such cases is to prepare students for the application of theoretical knowledge in practice in a real environment (Zotov, 2021).

- Educational cases aimed at learning certain activities; they practice the automatic skills and ways to find solutions (Kobayashi, 2018). When working with such cases, it is important to practice the skills of synthesis, to combine individual cases into typical ones, to understand the causes and factors, and the possible consequences.

- Scientific cases focused on the research work (Kobayashi, 2018).

The typology of cases is based on the source of their origin. The main sources of cases are considered to be education, science, literature, social life, etc. (Moreira, 2017).

3. Structurally, cases should consist of the following parts: a description of the problem situation (usually ambiguous, one that requires students to develop several solutions), the assignment to it, additional information needed to find the right solution (Hamilton \& Corbett-Whittier, 2013; Smoliak, 2021). The case can be presented in electronic (using multimedia, audio-visual means) or printed form.

Regarding the stages of working with cases, they can be formally divided as follows: acquaintance with the problem situation and its analysis, search for a solution, justification of advantages and disadvantages of each argument, evaluation of alternative solutions, presentation of results and their evaluation, summarizing ((Fretschner \& Lampe, 2019; Vinokurova et al., 2020). The teacher should model and direct the process of working with cases, so he/she is required to carefully prepare and fully master all the necessary materials (Harrison et al., 2019; Hoffer, 2020).

According to the study, we can say that modern domestic and foreign higher education is characterized by the development and implementation of leading European practices in the educational process, which, in turn, are based on competence, activity and personality-oriented approaches. This means that, along with special knowledge and skills, a qualified specialist must confidently use all of them in his/her work. Besides, he/she needs knowledge of strategy and tactics, which further ensure the effective realization of his/her competence.

The case method is also effective for the development of real professional skills. Working on case studies requires good organizational and time management skills. The case method improves students' skills of written and oral communication, as well as cooperation and teamwork.

Working with case studies should provide students with the opportunity to use the professional knowledge gained during theoretical training, as this is how new material necessary for further professional activity will be learnt and solidified (Smoliak, 2021). Besides, the case involves the development of coherent, logically structured monologue and dialogic professional speech, as the solution of the problem situation requires the need to speak before the audience, justifying and arguing own opinion. This is how professional skills are formed and developed.

A variety of materials in the professional sphere can be the sources of cases: scientific and periodical publications, economic documentation, news, records of business negotiations, etc. (Spirina, 2018). In order to be most effective in applying this method, other modern methods can be added and integrated, including brainstorming, professional discussions, situational modelling, etc. (Latusek, 2017).

In general, the introduction of case techniques in the higher education system is marked by the following positive aspects: this stimulates the development of abstract thinking; gives the opportunity to practice the obtained theoretical knowledge while solving problems in the professional sphere, does not limit the creative abilities of students (Bei, 2021; Bystritskaya et al., 2015; Foster \& Carboni, 2009).

We can draw a number of diagnostic conclusions on the basis of the received distributions of results of development of students' projective culture, which have a high validity and reliability. Quantitative data show that the cognitive component represented by projective competence has grown as a result of experimental work. The emotional and value component, expressed by the student's sense-creation, has changed as follows: the high level increased, the medium and low levels decreased. The third component of projective culture - projective-reflexive, represented by 
control and self-assessment actions of students and their self-presentation - changed as follows: the high level increased and the low level decreased. So, the presented digital and factual data testify to the effectiveness of the conceptual provisions of the process of developing a projective culture, as well as indicate the high practical significance of the study. The analysis of the conducted research proves the efficiency of the dynamic structural-substantive model, which, taking into account the pedagogical support, creates favourable conditions for the development of the projective culture of students in the educational environment of HEIs.

\section{Conclusions}

The research topicality is due to the fact that integrating into the system of traditional teaching methods, the case method can successfully combine educational and research content. Analysing the advantages of using the case method during the professional training of students in HEIs, we can identify the following: the ability to solve a number of problems at different levels; the possibility of creating a special educational environment and conditions for the active application of the acquired knowledge in practice; the possibility of active involvement of all participants in joint activities aimed at finding the best ways to solve the problem situation; promoting better and more effective consolidation and development of skills in various activities; development of creative and critical thinking.

The case method contributes to the deeper development of practical and analytical skills in future specialists in the chosen field of activity. It is possible to apply the case method at different stages of the educational process, step by step, gradually - from the simplest problem situations to complex ones. The case method reflects current trends in the chosen field of study, which provides an opportunity to gain important and in-demand skills and knowledge. Despite the relevance and rapid spread of this method in education, there are, however, some difficulties, in particular: when creating a case, you should take into account professional language features, you cannot use outdated and uninteresting material that requires more skill from teachers.

The study showed that the component of project self-presentation and its implementation in the student's life, indicators of the formation of control and self-assessment actions - their self-presentation - is of great importance for assessing the effectiveness of research and experimental work. This was reflected in an increased high level to $35.5 \%$, a decreased medium level to $38 \%$, and a slight increase in all levels in the experimental group students. Besides, the effectiveness of the case method is manifested when it is combined with other teaching methods, but in practice we do not always have a combination of different methods, which does not fully ensure the expected effectiveness of the learning process.

The results of the study may be of interest to employees of the educational field, students, managers, teachers of HEIs. The approbation of the presented research methods and their statistical processing is of particular value. The limitation of the study was primarily due to quarantine restrictions. This circumstance complicated the process of sampling, testing and conducing a survey. Hence, it can be stated that further research can deal with the development and implementation of case systems in accordance with certain majors, taking into account future professional activities. Further research can also cover interdisciplinary and interdepartmental coordination during case planning and development. Further research should also focus, on the one hand, on exploring other effective methods of training managers in the MBA programme. On the other hand, it is necessary to pay attention to the use of case methods in the training of specialists in other areas.

\section{References}

Akipova, Yu. (2020). Case technology in English lessons: to apply or not? Trends in the Development of Science and Education, 68(4), 6-14. https://doi.org/10.18411/lj-12-2020-135

Andersen, E., \& Sciano, B. (2017). Teaching with cases: A practical guide. Massachusetts: Harvard Business Publishing.

Bei, X. (June 4, 2021). Case method in online entrepreneurship business courses. Retrieved from https://www.colorado.edu/center/teaching-learning/2021/06/04/case-method-online-entrepreneurship-business-c ourses

Bystritskaya, E. V., Arifulina, R. U., \& Aksenov, S. I. (2015). Case technology in formation of professional competences of physical education teacher. Professional Competence, 39-41.

Daradkeh, Yo. I., \& Rakhimbekova, S. (2017). The use of Case-technology in teaching. International Journal of Open Information Technologies, 5(7), 73-79. 
Dian, J. (2020). IOT use cases \& technologies. Retrieved from https://www.researchgate.net/publication/346545159_IOT_Use_Cases_Technologies

Filimonova, T. (2021). Case technologies in the process of training future primary school teachers. Humanities science current issues, 6, 222-226. https://doi.org/10.24919/2308-4863/35-6-32

Foster, P., \& Carboni, I. (2009). Using student-centered cases in the classroom. An action inquiry approach to leadership development. Journal of Management Education, 33, 676-698. http://dx.doi.org/10.1177/1052562908328747

Fretschner, M., \& Lampe, H. W. (2019). Detecting hidden sorting and alignment effects of entrepreneurship education. Journal of Small Business Management, 57(4), 1712-1737. https://doi.org/10.1111/jsbm.12448

Hamilton, L., \& Corbett-Whittier, C. (2013). Using case study in education research. SAGE Research Methods in Education. https://dx.doi.org/10.4135/9781473913851

Harrison, K. (2019). Rude or shrewd? Reframing media devices as care structures and child use as accommodation. Journal of Children and Media, 13(3), 367-375. https://doi.org/10.1080/17482798.2019.1628192

Harrison, K., Vallina, L., Couture, A., Wenhold, H., \& Moorman, J. D. (2019). Sensory curation: Theorizing media use for sensory regulation and implications for family media conflict. Media Psychology, 22(4), 653-688. https://doi.org/10.1080/15213269.2018.1496024

Hoffer, E. R. (2020). Case-based teaching: using stories for engagement and inclusion. International Journal on Social and Education Sciences, 2(2), 75-80.

Hua, S., \& Ren, Z. (2020). "Online+Offline" Course teaching based on case teaching method: A case study of entrepreneurship education course. International Journal of Emerging Technologies in Learning (iJET), 15(10), 69-85.

Huang, Ch.-H., Hsiao, L. H. C., \& Ko, Sh.-L. (2021). Effect of applying case method to anti-corruption education on learning motivation and learning effectiveness. Revista de Cercetare şi Intervenţie Socială, 73, 276-287.

Kobayashi, A. (2018). Investigating the effects of metacognitive instruction in listening for EFL learners. The Journal of Asia TEFL, 15(2), 310-328. https://doi.org/10.18823/asiatefl.2018.15.2.4.310

Lang, G. (2014). Use case driven educational content modeling with UML. 2th International Conference on Emerging eLearning Technologies and Applications. https://doi.org/10.1109/ICETA.2014.7107600

Latusek, D. (2017). Case studies as a teaching tool in management education. Retrieved from https://faculty-research.esmt.berlin/sites/faculty/files/full_text_upload/Combining-Case-Teaching-and-Case-Wri ting-Creatively-1.pdf

Mahdi, O. R., Nassar, I. A., \& Almuslamani, H. A. I. (2020). The role of using case studies method in improving students' critical thinking skills in higher education. International Journal of Higher Education, 9(2), 297-308.

Moreira, F. (2017). Teaching and learning modelling and specification based on mobile devices and cloud: A case study. International Journal of Technology and Human Interaction, 13(4), 33-49. https://doi.org/10.4018/IJTHI.2017100103

Nowiński, W., Haddoud, M. Y., Lančarič, D., Egerová, D., \& Czeglédi, C. (2019). The impact of entrepreneurship education, entrepreneurial self-efficacy and gender on entrepreneurial intentions of university students in the Visegrad countries. Studies in Higher Education, 44(2), 361-379. https://doi.org/10.1080/03075079.2017.1365359

Plakhina, L. (2017). Application case-technology in the discipline "psychology pf professional education”. Aktuálni pedagogika, 2, 79-85. https://doi.org/10.24045/ap.2017.1.11

Roszkowska, E., \& Filipowicz-Chomko, M. (2021). Measuring sustainable development using an extended Hellweg method: A Case study of education. Social Indicators Research, 153, 299-322. https://doi.org/10.1007/s11205-020-02491-9

Smoliak, P. (2021). Generalization of experience in usage of case technology in the formation of student's social skills. Pedagogy and educational management review, 3(5), 4-13. https://doi.org/10.36690/2733-2039-2021-3-4

Spirina, M. (2018). The use of case-technologies in educational space of the university. Scientific Research and Development. Socio-Humanitarian Research and Technology, 7(2), 55-61. https://doi.org/10.12737/article_5b28c277e84c43.72281899 
Talukdar, M. R. I. (2020). When the case creates a competitive advantage. Asian Case Research Journal, 24(1), 97-109. https://doi.org/10.1142/S0218927520500042

Trejo-Pechi, C. J. O., \& White, S. (2017). The use of case studies in undergraduate business administration. RAE-Revista de Administração de Empresas, 57(4). https://doi.org/10.1590/S0034-759020170405

Vinokurova, N. V., Mikhailova, I. V., Kuzmicheva, N. A., \& Voronkova, I. P. (2020). Case method as a pedagogical technology in the study of chemical disciplines at the faculty of pharmacy. International Research Journal, 5(95-3), 88-91. http://dx.doi.org/10.23670/IRJ.2020.95.5.099

Wei, Y. D., \& Wu, T. J. (2019). Research of innovation and entrepreneurship education into professional education. Journal of Shenyang Institute of Engineering, 15(4), 532-535.

Zotov, V. (2021). Case technologies in education of students in specialist field "state and municipal management". Municipal Academy, 1, 26-33. https://doi.org/10.52176/2304831X_2021_01_26

\section{Copyrights}

Copyright for this article is retained by the author(s), with first publication rights granted to the journal.

This is an open-access article distributed under the terms and conditions of the Creative Commons Attribution license (http://creativecommons.org/licenses/by/4.0/). 